ف COLUMBIA |SIPA

Center for Development Economics and Policy

CDEP-CGEG WORKING PAPER SERIES

CDEP-CGEG WP No. 33

Disease and Gender Gaps in Human Capital Investment: Evidence from Niger's 1986 Meningitis Epidemic

Belinda Archibong and Francis Annan

January 2017

de COLUMBIA |SIPA

Center on Global Economic Governance 


\title{
Disease and Gender Gaps in Human Capital Investment: Evidence from Niger's 1986 Meningitis Epidemic*
}

\author{
Belinda Archibong ${ }^{\dagger}$ \\ Barnard College
}

\author{
Francis Annan \\ Columbia University
}

January 30, 2017

\begin{abstract}
This paper examines whether disease burdens, especially prevalent in the tropics, contribute significantly to widening gender gaps in educational attainments. We estimate the impact of sudden exposure to the 1986 meningitis epidemic in Niger on girls' education relative to boys. Our results suggest that increases in meningitis cases during epidemic years significantly reduce years of education disproportionately for primary school-aged going girls in areas with higher meningitis exposure. There is no significant effect for boys in the same cohort and no effects of meningitis exposure for non-epidemic years. Our findings have broader implications for climate-induced disease effects on social inequality.
\end{abstract}

JEL classification: I14, I24, O12, O15, J16

Keywords: Education, Meningitis, Health, Human Capital, Gender Gap, Niger

${ }^{*}$ Acknowledgments: We are grateful to Carlos Perez, Madeleine Thomson, Nita Bharti, the Ministry of Public Health in Niger and World Health Organization (WHO) for the data on meningitis used in this study. Thanks to discussant Linda Loubert and participants at the NEA "Gender and Development in Africa" 2017 AEA session for useful comments and suggestions. Errors are our own.

${ }^{\dagger}$ Corresponding author. Barnard College. 3009 Broadway, New York, NY 10027, USA. ba2207@columbia.edu. 


\section{Introduction}

"In my community work I soon learned more about the barriers for girls in school. If families are going through a financial rough patch, they're more likely to pay fees for boys rather than for girls. If girls drop out of school, the family is eager to marry them off rather than have them sit around the house all day."

- Natasha Annie Tonthhola, BBC News

There is a vast literature on the positive economic impacts of investment in education (Becker, Murphy, and Tamura, 1990). In developing countries, where notable gender gaps in educational attainment still remain, the potential economic gains from educating girls are significant (Schultz, 2002). Though gaps in primary school enrollment have been closing, largely due to national policies promoting free primary education, gaps in educational attainment still remain, partly driven by lower primary completion rates and lower secondary school enrollment rates for girls relative to boys in poorer countries concentrated in Africa and Asia ${ }^{1}$. Some of the reasons given for this persistent gap and associated lower investment of parents in female versus male children have been direct costs related to school fees and opportunity costs related to early marriage of girls, foregone earnings of girls' labor, and gendered expectations of the division of household labor, with girls expected to care for younger siblings and contribute disproportionately to other unpaid domestic work (Schultz, 2002; Hartmann-Mahmud, 2011).

Another strand of literature has examined the relationship between health shocks and investment in human capital with findings showing a negative relationship between disease/mortality rates and investments in education (Miguel and Kremer, 2004; Almond, 2006; Glewwe and Miguel, 2007; Jayachandran and Lleras-Muney, 2009). However, the literature

\footnotetext{
${ }^{1}$ Source: OECD "Closing the Gender Gap" report
} 
has been thin in understanding how health shocks and disease burdens contribute to differences in educational attainment and investment in the human capital of girls relative to boys (Glewwe and Miguel, 2007). Estimating the contribution of health shocks to differential human capital investment by gender is especially important for developing countries in Africa and Asia where the combination of notable gender gaps in educational attainment and higher disease burdens in the tropics can impose a double cost for economic development.

This paper's main contribution is to estimate the effect of health shocks on the gender gap in educational attainment by exploiting a quasi-experiment, the 1986 meningitis epidemic in Niger. We estimate a difference-in-differences model, interacting an indicator for gender with a continuous cohort-based measure of meningitis exposure during the 1986 epidemic. We find that higher meningitis exposure during the epidemic reduced years of education for school-going aged girls at the time of the epidemic. Interestingly, there is no significant difference in the education of boys exposed to higher or lower meningitis incidence during the epidemic. These results have important implications: first, health shocks disproportionately impact investment in girls' education with direct and opportunity costs of investing in girls' education potentially higher during shocks. Second, a focus on improving attainment through free, mandatory primary education programs means that most of the investment in the education of girls will occur at the primary level in poorer countries. So disease shocks will have disproportionate effects on primary school aged girls, decreasing the likelihood of primary school completion and resulting in lower attainment for girls relative to boys. Third, our findings highlight the need for policies targeting both health and education concurrently to close the gap in educational attainment and maximize economic returns from the associated gains in human capital investment, particularly for poorer countries located in higher disease burden areas in the tropics. 


\section{Meningitis Epidemic in Niger}

Niger is located in the so-called 'meningitis belt' that runs across sub-Saharan Africa (SSA), extending from Senegal in the west to Ethiopia in the far east ${ }^{2}$, where most epidemics of meningococcal meningitis occur (LaForce et al., 2009). The epidemic ${ }^{3}$ form of meningitis is caused by the bacterium Neisseria meningitidis and infection is associated with fevers, pain, reduced cognitive function, and in the worst cases, permanent disability and death. The epidemiology of the disease is complex and though incidence is often associated with higher dust concentrations and lower temperatures that come with the onset of the dry, Harmattan season in SSA, the mechanisms of transmission are not fully understood ${ }^{4}$. Additionally, though vaccines have been introduced to combat the spread of the disease since the first recorded cases in 1909 for SSA, effectiveness of the vaccines has been limited due to the mutation and virulence tendencies of the bacterium (LaForce et al., 2009).

Niger has experienced six epidemics since 1986, with the largest lag between epidemics occurring between the 1986 and subsequent 1993 epidemic $^{5}$. The 1986 epidemic was severe with 15,823 reported cases per 100,000 population and a mortality rate of about $4 \%$. Young children and teenagers are particularly at risk of infection during epidemic years, a fact that puts, and has historically placed, a major share of Niger's population ${ }^{7}$ at particular disadvantage during epidemics. Domestic, interdistrict migration is limited in Niger ${ }^{8}$ and population

\footnotetext{
${ }^{2}$ See Figure A1 in the Appendix. Over 95\% of the Nigerien population resides in the meningitis belt, which is the less desert ecological region of the country. Source: Author's estimates from DHS.

${ }^{3}$ Where epidemics are defined in the SSA context as greater than 100 cases per 100,000 population nationally within a year by the World Health Organization (WHO) (LaForce et al., 2009).

${ }^{4}$ Direct transmission is through contact with respiratory droplets from infected individuals. See LaForce et al. (2009) for details.

${ }^{5}$ Epidemic years include 1986, 1993-1996 and 2000 between 1986-2008. See Figure A2 in the Appendix.

${ }^{6}$ Calculated from WHO data, details presented in Section 3.

${ }^{7}$ Where the median age has remained at 15 years old for over a decade. Source: DHS and UNICEF statistics.

${ }^{8}$ With most migration consisting of young male seasonal migrants in the northern desert regions, traveling internationally to neighboring countries for work during during dry months (Afifi, 2011).
} 
size across districts has been stable with the distribution almost entirely unchanged since 1986 and a correlation of .99 and $.97(p<.001)$ between 1986 district populations and 1992 and 1998 populations respectively ${ }^{9}$. We assess individual exposure to the 1986 meningitis epidemic based on a geographically based assignment at the district level, given low levels of interdistrict migration in the country.

\section{Data and Cohorts}

We combine district level records on meningitis cases per 100,000 population from the World Health Organization (WHO) and the Ministry of Public Health in Niger with individual and district level data on education and demographics from the Nigerien Demographic and Health Surveys (DHS). The district level DHS data is available for 2 survey rounds in 1992 and 1998 (see Table A1 in the Appendix) and provide records for individuals in all 36 districts across the country (shown in Figure A4). Education measures the number of years of education that an individual has completed, and we limit our sample to the cohort born between 1960-1992 which allows us to include cohorts that were school going age during the 1986 meningitis epidemic. Using data from Niger also allows us to exploit homogeneity in religious, ethnic and income characteristics across individuals in the country to more cleanly capture the effect of meningitis epidemic exposure ${ }^{10}$.

We rely on information about the birth year to construct school-aged specific cohorts and their exposure to the 1986 meningitis epidemic. Three categories are defined which include ages 0-5, 6-12 and 13-20 with reference to 1986 . These age bands reference the Nigerien school going requirements/context where 6-12 and 13-20 age categories correspond to primary and secondary school going ages respectively, and 0-5 are non-school going. While

\footnotetext{
${ }^{9}$ Source: Author's estimates from DHS data.

${ }^{10}$ Niger is $98 \%$ muslim, over $50 \%$ Hausa and has a majority poor, agricultural population. Source: US Department of State, CIA.
} 
the mandatory school going start age is 7, we allow our primary school category to start from 6 to control for early school going children. The bands contain enough observations to ensure that estimations are not done on empty cells and also help to control for age misreporting in the sample. Our overall results are insensitive to marginal changes in the age cutoffs. We predict that the largest magnitudes in reduction of female education during the epidemic will be for primary school aged going children given statistics on low secondary school enrollment rates in the country ${ }^{11}$. Conversely, we should see no or little effect of meningitis exposure on years of education for non-school aged girls (between ages 0-5) during the epidemic year.

\section{Empirical Framework}

We estimate panel regressions of school-aged specific cohorts $a$ linking years of education for individual $i$ in district $d$ at survey round $r$ to measures of meningitis exposure MENIN $_{a d t}$ that are interacted with the gender of the individual female $i g$ :

$$
\text { education }_{i a d r g}=\beta_{a} \mathrm{MENIN}_{a d t} \times \text { female }_{i g}+\mu_{d}+\delta_{r}+\delta_{t}+\epsilon_{i a d r g}
$$

where $t$ and $g$ index the birth year and gender respectively. This specification includes district fixed effects $\mu_{d}$ which capture unobserved differences that are fixed across districts. The birth year and survey round fixed effects, $\delta_{t}$ and $\delta_{r}$ respectively, control for changes in national policies (e.g. immunization campaigns), potential life cycle changes across cohorts and other macro factors. Note that the birth year fixed effect subsumes cohort specific dummies since cohorts are defined based on birth year and the meningitis reference year 1986. The model also includes uninteracted terms for gender and meningitis exposure.

Our key parameter of interest is $\beta_{a}$, which is allowed to vary across cohorts. This measures the impact of MENIN on female respondents' education relative to their male

\footnotetext{
${ }^{11}$ Source: UNICEF statistics.
} 
counterparts, using variation across districts and the 1986 meningitis epidemic and identified based on standard assumptions in a difference-in-differences model. MENIN is measured in two ways. In the first case, we calculate the mean weekly cases of meningitis per 100,000 population recorded in a district (MENIN Cases). The second case modifies the first measure by interacting it with the number of months for which meningitis incidence is strictly positive (MENIN Intensity). The implied key variable of interest is therefore constructed by interacting the MENIN measures with gender. Estimations are done using OLS and standard errors are clustered at the district level. Robustness checks and falsification tests on our identifying assumptions are presented in the results section.

\section{Results}

Table 1 reports estimates from two specifications for our two measures of meningitis exposure (i.e., MENIN Cases; MENIN Intensity) using 1960-1992 cohorts. Columns 1a and 1c display results for the linkages between educational attainment, gender and meningitis exposure at cohorts-level. The gender variable is negative and significant in both columns, documenting the existing gender gap between males and females in favor of males. Meningitis exposure across almost all cohorts is negative and insignificant. It is barely significant at $10 \%$ only in the MENIN Intensity measure for primary school cohorts.

Our main results are in columns $1 \mathrm{~b}$ and $1 \mathrm{~d}$ of Table 1 where we interact the meningitis exposure measures with gender to examine gender-differentiated impacts of the meningitis burden on educational investments. Gender is negative and significant. What is striking is that only interaction terms for the school going cohorts are negative and strongly significant at conventional levels. The interaction estimates are economically large in magnitude especially in the MENIN Cases measure. Interpreting the results from the MENIN Cases measure in column 1b, a case increase in the mean weekly meningitis cases per 100,000 pop- 
ulation in each district is associated with a reduction of -.042 years of schooling or a $3 \%$ to $4 \%$ decrease in years of education ${ }^{12}$ per case exposure, relative to the mean for female respondents of primary school going age during the epidemic year. Primary school aged female respondents in higher case exposure districts experience significant reductions in their years of education relative to their counterparts in lower case exposure districts during the epidemic year. Similar results are found for the secondary school aged female sample, with increases in meningitis case exposure associated with a reduction of -.03 years of schooling or $2 \%$ to $3 \%$ decrease in years of education, per case exposure relative to the mean for the female cohort. Reassuringly, the interaction is not significant for non-school going aged female respondents at the time of the epidemic.

We conduct various falsification/sensitivity tests. First, the results are robust to small changes/modifications in cohort age cutoffs (Table A2). Our main results are derived using the definition of cohorts based on the 1986 epidemic. In alternate specifications presented in Table A3 in the Appendix, we examine school going and non-school going aged cohorts based on the 1990 non-epidemic year. Table A3 reports estimates for cohorts defined based a reference non-epidemic year 1990. We find no effect of meningitis exposure for the primary school aged category across all relevant specifications, which is what we would expect ${ }^{13}$. There is evidence of effects for the secondary school aged category. The secondary cohorts are essentially capturing effects of initial exposure to the 1986 epidemic when such cohorts were in primary school ${ }^{14}$. The sign on the $0-5$ group is significantly positive which suggests positive investment in education during non-epidemic years ${ }^{15}$. These robustness checks and

\footnotetext{
${ }^{12}$ Relative to the unconditional and conditional mean years of education respectively.

${ }^{13}$ Note since attainment is cumulative and there is slight serial correlation in meningitis exposure across districts (randomly distributed over years so it is uncertain which years will be correlated with which) in certain years- for example between 1986 and 1990, the correlation is .46 $(p<.01)$, some of this effect captures a long run effect of initial exposure in 1986 since the primary school aged cohort in 1990 includes some of the non-school going aged populations in 1986.

${ }^{14}$ Again due to slight serial correlation between 1986 and 1990 exposure as explained in the previous footnote.

${ }^{15}$ It could also suggest a reversal in district exposure during the 1993-1996 epidemics for respondents from
} 
falsification results make it less likely that we are picking up any spurious/confounding effects in our main results.

Our results suggest that meningitis epidemic health shocks disproportionately impact investment in girls' education potentially due to increases in the direct and opportunity costs of parental investment in girls' education during epidemic years. Epidemic years and higher than expected meningitis exposure might mean a contraction of the household budget constraint due to lost wages and increased health costs associated with the epidemic. Direct costs associated with fees might be higher when the household budget constraint shifts inward. Opportunity costs might rise with girls' labor increasingly commanded to care for sick family members or act as substitute labor for sick family members during the epidemic years $^{16}$.

\section{Conclusion}

Our analysis of the effects of exposure to the 1986 meningitis epidemic on educational attainment of school aged girls in Niger, reveals that the gender gap widened during the epidemic year. The effect is particularly significant for primary school aged girls at the time of the epidemic, since most of the investment in education happens at the primary level. We find a significant decrease in years of education for school aged female respondents at the time of the epidemic with no significant effect for their male counterparts. Given the evidence on the intergenerational returns to female education and the potential economic returns to closing the gender gap, these results highlight the need for dual policy addressing both education and health to target the gender gap in educational attainment.

Ongoing research examines the cumulative effect of epidemic exposure on female edu-

these districts who would be in the primary school aged categories during that period. We address the subject of cumulative effects in ongoing work.

${ }^{16}$ Hartmann-Mahmud (2011) documents this phenomenon in her case study research interviewing Nigerien women. 
cation as well as the impact of siblings on the allocation of investment in education between male and female children. An important contribution of the paper is to show that disease burdens and health shocks contribute significantly to widening gender gaps in educational attainment with associated implications for development in poorer countries. This line of research has broader implications for climate-induced disease effects on social inequality. 
Table 1: Difference in Difference Estimates of the Differential Impact of Meningitis Exposure on Education (1986 Epidemic Year), MENIN x Female

\begin{tabular}{lcccc}
\hline \hline & \multicolumn{3}{c}{ Dependent Variable: Years of Education } \\
\cline { 2 - 5 } & \multicolumn{2}{c}{ MENIN Cases } & \multicolumn{2}{c}{ MENIN Intensity } \\
& $(1 \mathrm{a})$ & $(1 \mathrm{~b})$ & $(1 \mathrm{c})$ \\
\hline Female & $-0.646^{* * *}$ & $-0.499^{* * *}$ & $-0.646^{* * *}$ & $-0.514^{* * *}$ \\
Meningitis exposure at ages 0-5 & $(0.050)$ & $(0.076)$ & $(0.050)$ & $(0.071)$ \\
& -0.001 & 0.002 & -0.0002 & 0.0001 \\
x Female & $(0.003)$ & $(0.004)$ & $(0.0003)$ & $(0.0004)$ \\
& & -0.006 & & -0.0005 \\
Meningitis exposure at ages 6-12 & -0.025 & $(0.005)$ & & $(0.001)$ \\
& $(0.016)$ & -0.003 & $-0.002^{*}$ & -0.0005 \\
x Female & & $(0.020)$ & $(0.001)$ & $(0.002)$ \\
& & $-0.042^{* * *}$ & & $-0.004^{* * *}$ \\
Meningitis exposure at ages 13-20 & -0.044 & -0.027 & -0.004 & $(0.001)$ \\
& $(0.029)$ & $(0.029)$ & $(0.002)$ & -0.002 \\
x Female & & $-0.030^{* * *}$ & & $-0.002)$ \\
& & $(0.010)$ & & $\left(0.003^{* * *}\right.$ \\
Constant & $1.032^{* * *}$ & $0.954^{* * *}$ & $1.003^{* * *}$ & $0.934^{* * *}$ \\
District fixed effects & $(0.199)$ & $(0.215)$ & $(0.185)$ & $(0.197)$ \\
Year fixed effects & Yes & Yes & Yes & Yes \\
Year of birth fixed effects & Yes & Yes & Yes & Yes \\
\hline Observations & Yes & Yes & Yes & Yes \\
$\mathrm{R}^{2}$ & 47,697 & 47,697 & 47,697 & 47,697 \\
\hline \hline
\end{tabular}

Notes: Regressions estimated by OLS. Robust standard errors in parentheses clustered by district. Dependent variable is years of education across all specifications. MENIN cases is the meningitis exposure explanatory variable defined as average district level weekly case (per 100,000 population) exposure for cohort at specified ages during the 1986 epidemic year. MENIN intensity is the meningitis exposure explanatory variable measured as district level case exposure for cohort at specified ages during the 1986 meningitis epidemic year multiplied by number of months of exposure (with greater than zero cases). Mean level of education in the sample is 1.22, and the standard deviation is 2.7. Mean level of education for boys in the sample is 1.51 and the mean level of education for girls in the sample is 0.94 . The estimates represent $3 \%$ to $4 \%$ and $2 \%$ to $3 \%$ reduction in education for girls in the primary school going age sample (ages 6-12) and secondary school going age sample (ages 13-20) respectively relative to the unconditional and conditional means. ${ }^{* * *}$ Significant at the 1 percent level, ${ }^{* *}$ Significant at the 5 percent level, * Significant at the 10 percent level. 


\section{References}

Afifi, Tamer. 2011. "Economic or environmental migration? The push factors in Niger." International Migration 49 (s1): e95-e124.

Almond, Douglas. 2006. "Is the 1918 Influenza pandemic over? Long-term effects of in utero Influenza exposure in the post-1940 US population." Journal of political Economy 114 (4): $672-712$.

Becker, Gary S, Kevin M Murphy, and Robert Tamura. 1990. "Human Capital, Fertility, and Economic Growth." Journal of Political Economy pp. S12-S37.

Glewwe, Paul, and Edward A Miguel. 2007. "The impact of child health and nutrition on education in less developed countries." Handbook of development economics 4: 3561-3606.

Hartmann-Mahmud, Lori. 2011. "Pounding millet during school hours: Obstacles to girls? Formal education in Niger." The European Journal of Development Research 23 (3): 354370.

Jayachandran, Seema, and Adriana Lleras-Muney. 2009. "Life Expectancy and Human Capital Investments." The Quarterly Journal of Economics 124 (1): 349-397.

LaForce, F Marc, Neil Ravenscroft, Mamoudou Djingarey, and Simonetta Viviani. 2009. "Epidemic meningitis due to Group A Neisseria meningitidis in the African meningitis belt." Vaccine 27: B13-B19.

Miguel, Edward, and Michael Kremer. 2004. "Worms: identifying impacts on education and health in the presence of treatment externalities." Econometrica 72 (1): 159-217.

Schultz, T Paul. 2002. "Why governments should invest more to educate girls." World Development 30 (2): 207-225. 
Tonthola, Annie Natasha. 2016. "Natasha Annie Tonthola: My fight against Malawi's 'hyenas'." BBC News Magazine, October 25.

\section{A Appendix}

Table A1: Variable Means

\begin{tabular}{cccccccccc}
\hline \hline & Total population & & \multicolumn{3}{c}{ Males } & \multicolumn{3}{c}{ Females } \\
\hline & 1992 & 1998 & $1992-1998$ & 1992 & 1998 & $1992-1998$ & 1992 & 1998 & $1992-1998$ \\
\hline Population & & & & & & & & \\
\hline percent age 0-5 in 1986 & 0.24 & 0.24 & 0.24 & 0.24 & 0.24 & 0.24 & 0.24 & 0.23 & 0.23 \\
percent age 6-12 in 1986 & 0.21 & 0.18 & 0.19 & 0.21 & 0.17 & 0.19 & 0.21 & 0.19 & 0.2 \\
percent age 13-20 in 1986 & 0.16 & 0.18 & 0.17 & 0.15 & 0.16 & 0.15 & 0.18 & 0.20 & 0.19 \\
\hline Meningitis cases cohort exposure & & & & & & & & \\
\hline age 0-5 in 1986 & 2.47 & 2.54 & 2.5 & 2.51 & 2.67 & 2.58 & 2.43 & 2.42 & 2.43 \\
age 6-12 in 1986 & 2 & 1.84 & 1.93 & 2.10 & 1.68 & 1.91 & 1.91 & 1.98 & 1.94 \\
age 13-20 in 1986 & 1.52 & 1.99 & 1.73 & 1.36 & 1.77 & 1.54 & 1.67 & 2.19 & 1.91 \\
\hline Years of education & & & & & & & & & \\
\hline Control Cohorts: age 0-5 in 1986 & 0.40 & 1.95 & 1.09 & 0.46 & 2.33 & 1.3 & 0.33 & 1.58 & 0.89 \\
Treated Cohorts: age 6-12 in 1986 & 1.85 & 2.38 & 2.07 & 2.26 & 3.22 & 2.63 & 1.46 & 1.72 & 1.57 \\
Treated Cohorts: age 13-20 in 1986 & 1.99 & 1.83 & 1.91 & 2.69 & 2.58 & 2.64 & 1.43 & 1.32 & 1.37 \\
\hline
\end{tabular}

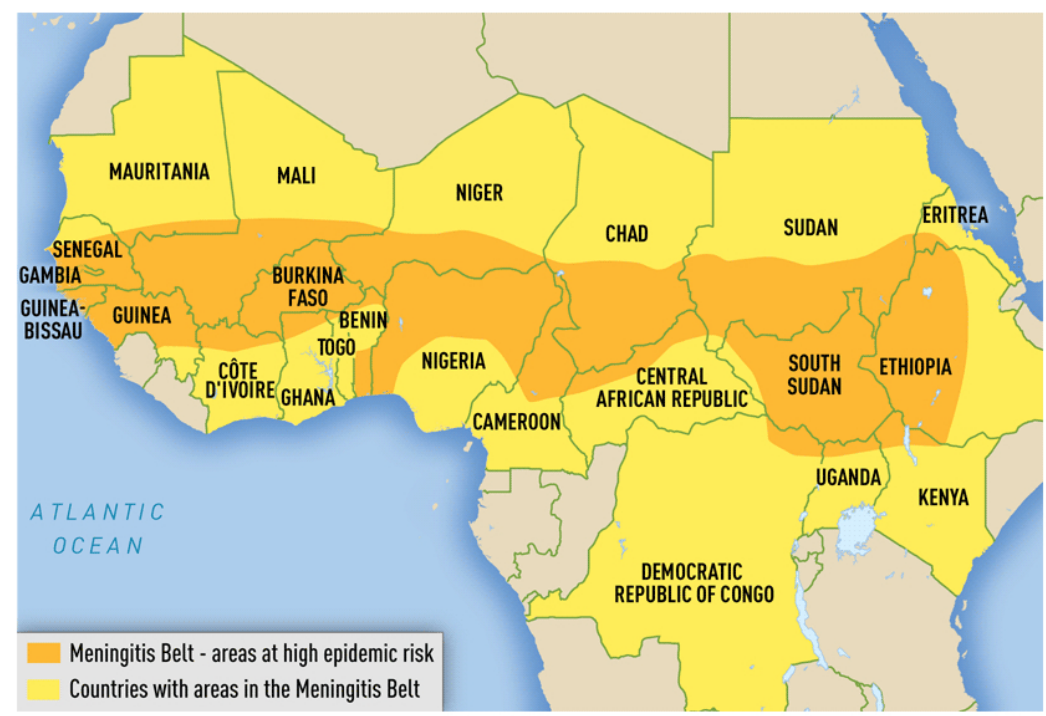

MAP 3-11. AREAS WITH FREQUENT EPIDEMICS OF MENINGOCOCCAL MENINGITIS'

1 Disease data source: World Health Organization. International Travel and Health. Geneva, Switzerland: 2012.

Figure A1: Areas with Frequent Epidemics of Meningococcal Meningitis ('Meningitis Belt') 
Table A2: Difference in Difference Estimates of the Differential Impact of Meningitis Exposure on Education (1986 Epidemic Year), Robustness Check

\begin{tabular}{lcccc}
\hline \hline & \multicolumn{3}{c}{ Dependent Variable: Years of Education } \\
\cline { 2 - 5 } & \multicolumn{2}{c}{ MENIN Cases } & $(3 \mathrm{c})$ & $(3 \mathrm{~d})$ \\
\hline Female & $(3 \mathrm{a})$ & $(3 \mathrm{~b})$ & $-0.645^{* * *}$ & $-0.547^{* * *}$ \\
& $-0.644^{* * *}$ & $-0.536^{* * *}$ & $(0.049)$ & $(0.064)$ \\
Meningitis exposure at ages 0-4 & $(0.049)$ & $(0.067)$ & 0.001 & $0.0005^{*}$ \\
& 0.005 & $0.005^{*}$ & $(0.0004)$ & $(0.0003)$ \\
x Female & $(0.004)$ & $(0.003)$ & & 0.0001 \\
& & 0.0004 & & $(0.001)$ \\
Meningitis exposure at ages $7-12$ & -0.024 & $-0.005)$ & $-0.002^{*}$ & -0.0004 \\
& $(0.015)$ & $(0.019)$ & $(0.001)$ & $(0.002)$ \\
x Female & & $-0.040^{* * *}$ & & $-0.003^{* * *}$ \\
& & $(0.012)$ & & $(0.001)$ \\
Meningitis exposure at ages 14-21 & -0.044 & -0.027 & -0.004 & -0.002 \\
& $(0.028)$ & $(0.027)$ & $(0.002)$ & $(0.002)$ \\
x Female & & $-0.030^{* * *}$ & & $0.003^{* * *}$ \\
& & $(0.009)$ & & $(0.001$ \\
Constant & $1.039^{* * *}$ & $0.982^{* * *}$ & $1.018^{* * *}$ & $0.967^{* * *}$ \\
District fixed effects & $(0.199)$ & $(0.210)$ & $(0.187)$ & $(0.195)$ \\
Year fixed effects & Yes & Yes & Yes & Yes \\
Year of birth fixed effects & Yes & Yes & Yes & Yes \\
\hline Observations & Yes & Yes & Yes & Yes \\
$\mathrm{R}^{2}$ & 47,697 & 47,697 & 47,697 & 47,697 \\
\hline \hline
\end{tabular}

Notes: Regressions estimated by OLS. Robust standard errors in parentheses clustered by district. Dependent variable is years of education across all specifications. MENIN cases is the meningitis exposure explanatory variable defined as average district level weekly case (per 100,000 population) exposure for cohort at specified ages during the 1986 epidemic year. MENIN intensity is the meningitis exposure explanatory variable measured as district level case exposure for cohort at specified ages during the 1986 meningitis epidemic year multiplied by number of months of exposure (with greater than zero cases). ${ }^{* * *}$ Significant at the 1 percent level, ${ }^{* *}$ Significant at the 5 percent level, ${ }^{*}$ Significant at the 10 percent level. 
Table A3: Difference in Difference Estimates of the Differential Impact of Meningitis Exposure on Education (1990 Non-Epidemic Year), Robustness Check

\begin{tabular}{lcccc}
\hline \hline & \multicolumn{3}{c}{ Dependent Variable: Years of Education } \\
\cline { 2 - 4 } & \multicolumn{2}{c}{ MENIN Cases } & \multicolumn{2}{c}{ MENIN Intensity } \\
& $(2 \mathrm{a})$ & $(2 \mathrm{~b})$ & $(2 \mathrm{c})$ & $(2 \mathrm{~d})$ \\
\hline Female & $-0.644^{* * *}$ & $-0.651^{* * *}$ & $-0.643^{* * *}$ & $-0.653^{* * *}$ \\
& $(0.050)$ & $(0.076)$ & $(0.049)$ & $(0.074)$ \\
Meningitis exposure at ages 0-5 & -0.065 & -0.122 & -0.011 & -0.016 \\
& $(0.091)$ & $(0.112)$ & $(0.011)$ & $(0.014)$ \\
x Female & & $0.113^{* *}$ & & $0.011^{* *}$ \\
& & $(0.045)$ & & $(0.004)$ \\
Meningitis exposure at ages 6-12 & -0.005 & 0.012 & -0.002 & -0.001 \\
& $(0.041)$ & $(0.055)$ & $(0.004)$ & $(0.006)$ \\
x Female & & -0.032 & & -0.002 \\
& & $(0.039)$ & & $(0.004)$ \\
Meningitis exposure at ages $13-20$ & 0.010 & 0.069 & 0.003 & 0.008 \\
& $(0.047)$ & $(0.058)$ & $(0.006)$ & $(0.007)$ \\
x Female & & $-0.108^{* * *}$ & & $-0.010^{* * *}$ \\
& & $(0.037)$ & & $(0.003)$ \\
Constant & $1.038^{* * *}$ & $1.042^{* * *}$ & $1.018^{* * *}$ & $1.024^{* * *}$ \\
& $(0.181)$ & $(0.193)$ & $(0.170)$ & $(0.181)$ \\
District fixed effects & Yes & Yes & Yes & Yes \\
Year fixed effects & Yes & Yes & Yes & Yes \\
Year of birth fixed effects & Yes & Yes & Yes & Yes \\
\hline Observations & 47,697 & 47,697 & 47,697 & 47,697 \\
$\mathrm{R}^{2}$ & 0.205 & 0.207 & 0.206 & 0.207 \\
\hline \hline
\end{tabular}

Notes: Regressions estimated by OLS. Robust standard errors in parentheses clustered by district. Dependent variable is years of education across all specifications. MENIN cases is the meningitis exposure explanatory variable defined as average district level weekly case (per 100,000 population) exposure for cohort at specified ages during the 1990 non-epidemic year. MENIN intensity is the meningitis exposure explanatory variable measured as district level case exposure for cohort at specified ages during the 1990 non-epidemic year multiplied by number of months of exposure (with greater than zero cases). Mean level of education in the sample is 1.22 , and the standard deviation is 2.7. Mean level of education for boys in the sample is 1.51 and the mean level of education for girls in the sample is 0.94 . *** Significant at the 1 percent level, ** Significant at the 5 percent level, *Significant at the 10 percent level. 


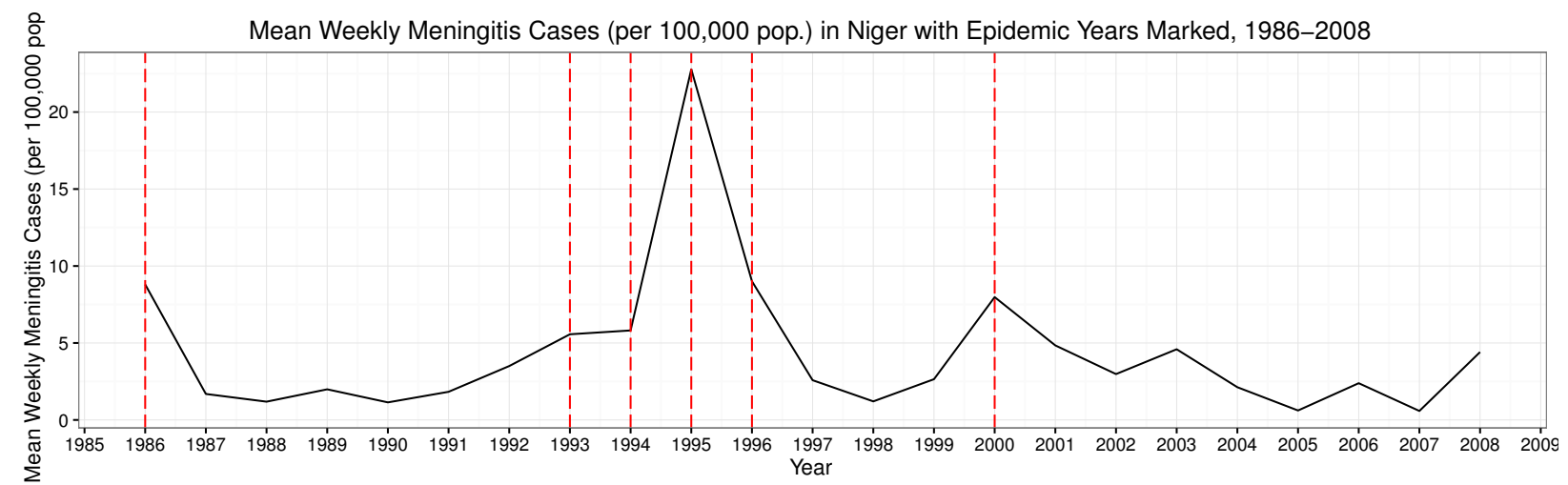

Figure A2: Niger Meningitis Cases with Epidemic Years Marked, 1986-2008

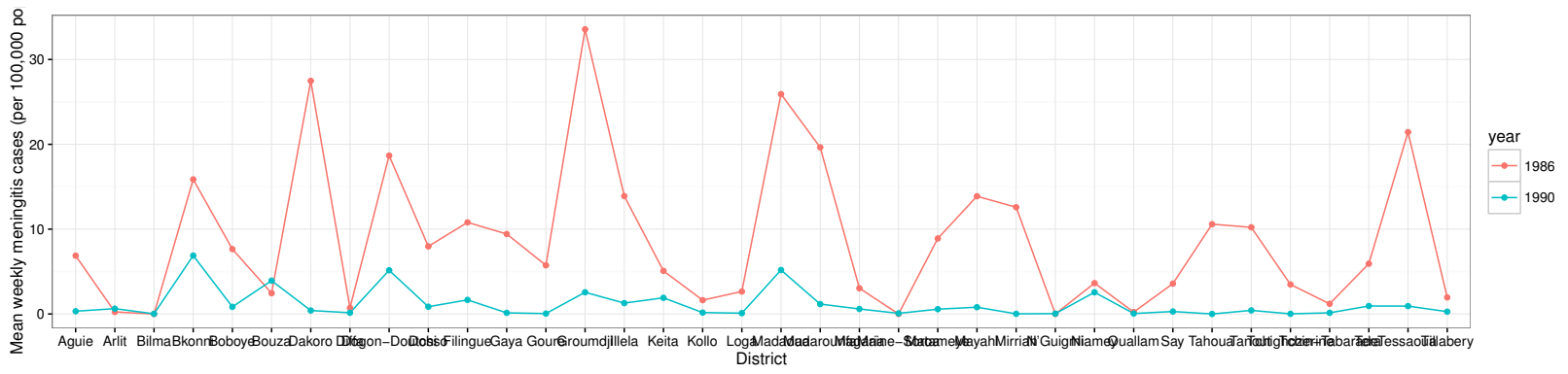

Figure A3: Niger Meningitis Cases by District in Epidemic (1986) and Non-epidemic (1990) Years 

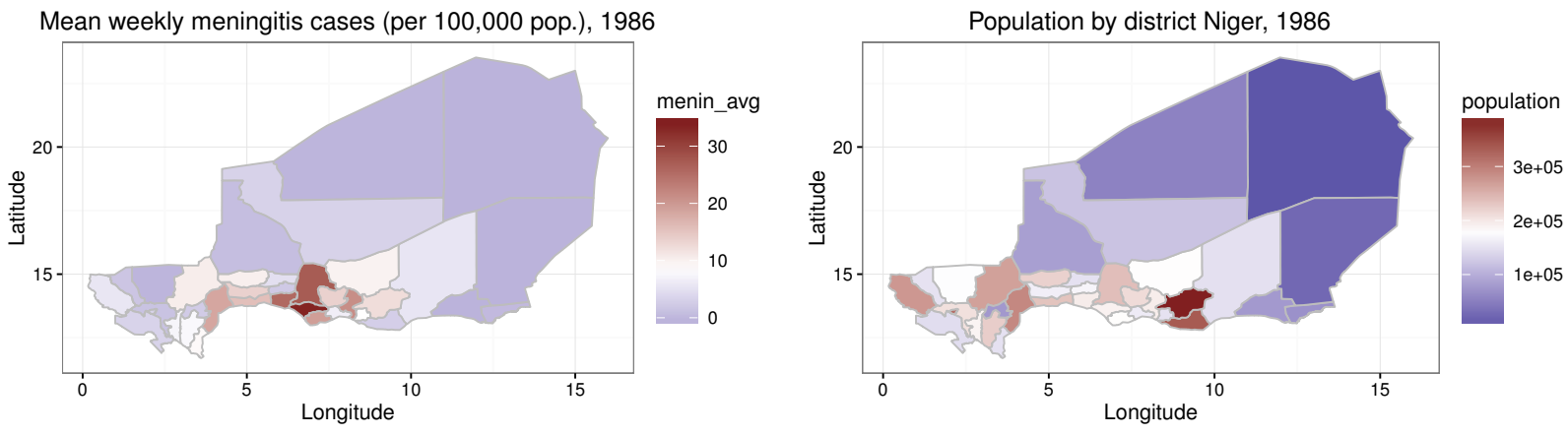

Mean weekly meningitis cases (per 100,000 pop.), 1990

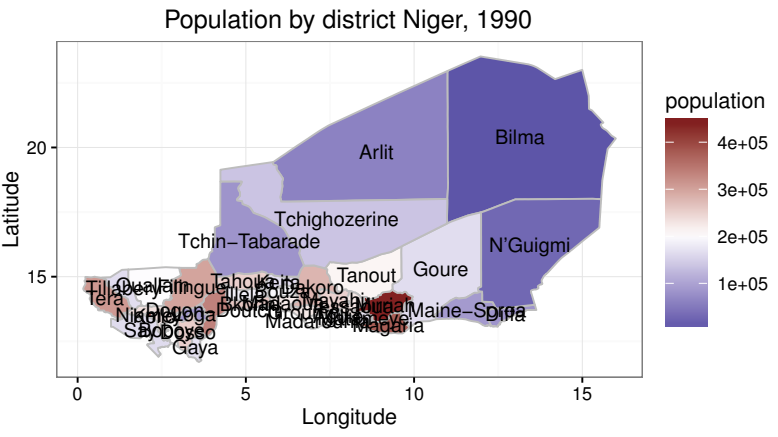

Figure A4: Niger Meningitis Cases and Population by District in Epidemic (1986) and Nonepidemic (1990) Years 